
\title{
25 Research Sourere \\ Occurrence and Risk of Organophosphate Flame Retardants in Multiple Urban Water of Beijing, China
}

\section{Weihua Cui}

China University of Geosciences Beijing

Shaoyong Lu ( $\sim$ lushy2000@163.com )

Chinese Research Academy of Environment Sciences https://orcid.org/0000-0001-8637-2515

\section{Research Article}

Keywords: Organophosphate flame retardants (OPFRs), Multiple urban water, Occurrence, Risk assessment, Beijing

Posted Date: June 7th, 2021

DOI: https://doi.org/10.21203/rs.3.rs-444690/v1

License: (c) (1) This work is licensed under a Creative Commons Attribution 4.0 International License. Read Full License 


\section{Abstract}

Investigating the organophosphate flame retardants (OPFRs) concentration and attenuation in multiple water of Beijing would provide valuable insight into OPFR management and reduction, thus, 6 OPFRs were determined by solid phase extraction-high performance liquid chromatography-tandem mass spectrometry to explore the pollution characteristics, and ecological risk of OPFRs. The results showed that 5 OPFRs were detected with a concentration ranging from ND to $394.77 \mathrm{ng} / \mathrm{L}$ except for tris(2,3dibromopropyl) phosphate (PDBP). The chloroalkyl phosphate was the main compound and tris(chloropropyl) phosphate (TCPP) was the most abundant OPFRs with the highest concentration. The concentration of OPFRs in surface water was higher than that in groundwater, and the concentration of chlorinated OPFRs in effluent from sewage treatment plants (STPs) was higher than that in influent. Ecological risk assessment showed that low risk of OPFRs for the organisms (algae, crustacean and fish).

\section{Introduction}

Organophosphate flame retardants (OPFRs) were widely used in plastics, textiles, electronic equipment, furniture, as well as construction (Stevens et al., 2006). Especially in industrial process, OPFRs are usually applied as antifoaming agents, and as flame retardants or plasticizers in consumer goods (Van der Veen and de Boer, 2012; Wei et al., 2015). OPFRs are generally classified into alkyl-OPFRs, aryl-OPFRs, chlorinated OPFRs, bromine OPFRs and other organophosphate esters. Because of the ban and restriction of partial bromine flame retardants in Stockholm Convention and RoHS of the European Union, chlorinated OPFRs such as tris(chloropropyl) phosphate (TCPP), tris(2-chloroethyl) phosphate (TCEP) and tris(dichloropropyl) phosphate (TDCPP) are widely used all over the world. Triphenyl phosphate (TPP) are widely used for computer screens and TV sets, and tis(2-butoxyethyl) phosphate (TBEP) is for floor polishes (Marklund et al., 2003).

Research shows the roles played by OPFRs are through physical mixture but not the chemical bond (Kemmlein et al., 2003; Kim and Kannan, 2018), thus the OPFRs may easily diffused into the environment through volatilization, abrasion and dissolution (Pang et al., 2016; Reemtsma et al., 2008). OPFRs may release from furniture, plastics, vehicle or industrial process into air, then afflux into surface water through wet deposition. OPFRs may directly discharged into municipal drainage network, and let it into surface water followed by STPs treatment. Several researches had shown that the ratio for mass loadings of TPP, TCPP, TDCPP and tri-n-butyl phosphate (TNBP) in STPs influent to the production was about $1.3-2.8 \%$ (Kim et al., 2017; Marklund et al., 2005; Schreder and La Guardia, 2014). As we surveyed and reported in other studies (Kim, et al., 2017), OPFRs cannot be treated in STPs and would finally transport into the potable water. Researches had reported the occurrence and distribution of OPFRs in air, water and STPs. The emission rate of OPFRs from building materials and electronic equipment could be up to 339 $\mu \mathrm{g} / \mathrm{m}^{2} / \mathrm{h}$ (Takigami et al., 2009). Möller et al. (2012) detected OPFRs in the atmosphere of the Arctic and Antarctic, demonstrating for the first time the long-range migration capability of OPFRs worldwide. A survey of the water quality of sewage treatment plants (STPS) in European countries showed that TCPP 
and TCEP could be detected in the effluent of most STPs at a concentration of several hundred $\mathrm{ng} / \mathrm{L}$ (Loos et al., 2013).

The high population density in cities has led to massive usage and discharge of OPFRs, making them widely disseminated in aquatic environments, such as drinking water, surface water, groundwater and municipal STPs (Reemtsma, et al., 2008; Shi et al., 2016). Studies have found that OPFRs exposed to the aquatic environments can enter the human body through food contamination, bioaccumulation, direct contact or ingestion, resulting in their detection in human hair, nails, urine and breast milk (Sundkvist et al., 2010; Liu et al., 2015; Zhang et al., 2016; He et al., 2018). Therefore, OPFRs pose a potential threat to human health and water environmental safety. As the capital of China, Beijing is the center of national political, economic, and cultural development, with a population of 21.73 million, and the population density (1324 people $/ \mathrm{km}^{2}$ ) ranks second among all cities (Ma et al., 2017a), thus it is conceivable that OPFRs would be used and consumed in significant quantities in this city (Shi et al., 2016). However, the current research on the occurrence and risk of OPFRs is still limited, especially lacking of comprehensive data on OPFRs exposure in different water bodies of high population density cities, such as Beijing.

Based above, we studied the distribution of six kinds of flame retardants such as TPP, tricresyl phosphate (TCP), TCPP, TCEP, TDCPP and tris(2,3-dibromopropyl) phosphate (TDBP) in typical urban water (surface river, underground water, sewage treatment plants (STPs)) of Beijing, China. Finally, environmental risk of OPFRs in water was evaluated to explore the impact of these chemicals on aquatic organisms. These results will help to understand the pollution levels and environmental risks of OPFRs in typical urban water bodies of modern metropolis, and provide data support for the establishment of OPFRs regulatory standards.

\section{Materials And Methods \\ 2.1 Sampling sites}

Seven sampling sites (W1 W7, according to the direction of water flow: Shahe floodgate/Mafang bridge/Xisishang village /Wenyu bridge/Yigezhuang bridge/Wenyu river Bridge/Beiguan floodgate) of surface water in the Wenyu River, five sampling sites (G1 G5; especially G3 is a multi-stage monitoring well with depths of $6.79 \mathrm{~m}, 11.64 \mathrm{~m}$ and $22.53 \mathrm{~m}$, and the corresponding sampling points are $\mathrm{G} 3 \mathrm{H}, \mathrm{G} 3 \mathrm{M}$ and G3L respectively) of groundwater in Shunyi District, three STPs ( $\mathrm{M}, \mathrm{H}$ and $\mathrm{C}$ ) from Miyun District, Haidian District and Chaoyang District including influents (M1, H1 and C1), effluents of secondary sedimentation ( $\mathrm{M} 2$ and $\mathrm{H} 2$ ) and effluents (M3, H3 and $\mathrm{C} 2$ ) in Haidian District were collected to investigate the OPFRs pollution in triplicate on winter, 2018. The detailed information of Wenyu River, groundwater and STPS were provided in Fig. 1 and Table S1, S2. The water samples were saved in the brown glass bottle at $4^{\circ} \mathrm{C}$ before laboratory analysis, which were treated within $24 \mathrm{~h}$ after being transported to the laboratory.

\subsection{Instruments and Quantification}


For the LC separation, UHPLC Dionex Ultimate 3000 (Thermo Scientific, San Jose, USA) equipped with cooling auto-sampler, column oven and UV detector were utilized. An ACQUITY UPLC BEH C18 Column $(2.1 \mathrm{~mm} \cdot 50 \mathrm{~mm}, 1.7 \mu \mathrm{m})$ was employed and the column temperature was set at $35^{\circ} \mathrm{C}$.

For the MS separation, the Q-Orbitrap mass spectrometer (Thermo Scientific, San Jose, USA) was equipped with a heat electrospray ionization (HESI) and operated in the full scan mode. The sheath gas, auxiliary gas and sweep gas was at a flow rate of 45,15 and 0 (arbitrary units), respectively. The spray voltage was set at $+3.00 \mathrm{kV}$. The capillary temperature and auxiliary gas heater temperature were maintained at $375^{\circ} \mathrm{C}$ and $300^{\circ} \mathrm{C}$, respectively. The S-lens RF level was set at $50 \mathrm{~V}$. Nitrogen was used for spray stabilization and as the damping gas in the C-trap. control (AGC) target (the number of ions to fill CTrap) was set at $1.0 \mathrm{e} 6$ with a maximum injection time (IT) of $100 \mathrm{~ms}$. The full MS scan ranges were set from 100 to $760 \mathrm{~m} / \mathrm{z}$ with a resolution of 70,000. In MS2 mode, samples were analyzed at 30 NCE (normalized collisional energy). All data collected in profile mode were acquired and processed by Thermo Xcalibur 3.0 software (Thermo Scientific, San Jose, USA).

Quantification using external standard was the approach to determine the concentration of OPFRs. The calibration curves for the OPs detection exhibited good linear relationship $\left(R^{2}>0.99\right)$. The limit of quantification (LOQ) calculated with a signal/noise ratio of 10 was $0.08 \sim 0.14 \mathrm{ng} / \mathrm{L}$.

\subsection{Sample preparation}

Method used to extract of OPFRs were followed the procedure by (Zhong et al., 2017) with small modification. After sample collection, urban water ( $1 \mathrm{~L}$ for each sample) was filtered through $0.45 \mu \mathrm{m}$ pore size glass microfiber filters, and extracted using solid phase extraction by gravity with HLB (hydrophilic-lipophilic balance) columns $\left(6 \mathrm{~cm}^{3}, 200 \mathrm{mg}\right)$. Before use, all the columns were conditioned by adding $6 \mathrm{~mL}$ of ethyl acetate and $6 \mathrm{~mL}$ of methanol. Then, the columns were drained and eluted with $10 \mathrm{~mL}$ of ethyl acetate. The extracts adjusted to $1 \mathrm{~mL}$ with methanol (nitrogen blow down).

\subsection{Statistical analysis}

The statistical significance of differences was evaluated by AVOVA, which was considered significant at $p<0.05$. The correlation analysis of OPFRs and environmental factors were carried out using SPSS 20.0 and Canoco 4.5 software.

\subsection{Ecological risk characterization}

The risk of OPEs for aquatic organisms was evaluated by the determination of risk quotient (RQ) values, as described by the previous reports (Yadav et al., 2018). RQ value of each compound in water was calculated using the following formula:

$\mathrm{RQ}=\mathrm{MEC} / \mathrm{PNEC}$

Where the MEC is the actual measured environmental concentration, PNEC is the no effect concentration, usually obtained by dividing the acute and chronic toxicity data (half lethal concentration LC50, half 
effect concentration EC50, etc.) by the assessment factor (AF). When $\mathrm{RQ}<0.1$, the risk is low or negligible; when $0.1<\mathrm{RQ}<1.0$, there is a medium risk; and when $\mathrm{RQ}>1.0$, it is considered to have a high risk.

\section{Results And Discussion}

\subsection{Occurrence of OPFRs in urban surface water and groundwater}

Six kinds of OPFRs was detected at seven sites in Wenyu river, as well as five sites for underground water (Fig. 2). The detection frequencies of three OPFRs (i.e. TPP, TCPP, TCEP) were $100 \%$, while those of TDBP, TDCPP and TCP were $0 \%, 28.57 \%$ and $35.71 \%$, respectively. Notably, TDBP was not detected in all of samples, which may be related with its high logk ow (4.29) and the substitutes of the new flame retardants (Table S2). The total concentration of five OPFRs in surface water of Wenyu river varied between 261.13 $\sim 581.69$ (mean: 374.05$) \mathrm{ng} / \mathrm{L}$, which was comparable to those of 14 OPFRs (37.20 510 ng/L) in river water located in New York state with high population (Kim and Kannan, 2018), but apparently higher than those in lake water from less populated cities of Germany (Regnery and Puttmann, 2010). This phenomenon reflects that frequent human activities in densely populated cities have important contribution to OPERs pollution of surface water. In contrast, the total concentrations of five OPFRs in underground water varied between $16.68 \sim 58.29$ (mean: 39.27) ng/L, which was significantly lower than that in surface water $(P<0.05)$.

Similar to other researches (Kim and Kannan, 2018), TCPP was the predominate OPFRs with a concentration of $203.70 ~ 394.77$ (mean-value: 262) ng/L in river and $12.02 \sim 52.43$ (mean-value: 28) $\mathrm{ng} / \mathrm{L}$ in underground water, followed by TCEP. Studies have confirmed that TCPP and TCEP appear to be the most ubiquitous in water and air (Reemtsma et al., 2008). The concentration-percent composition of these two OPFRs ([TCPP]+[TCEP]) accounted for $86.62 \sim 99.48 \%$ in river and $76.13 \sim 98.54 \%$ in underground water of the total, with an average of $91.65 \%$ and $86.50 \%$, respectively, partly because their high solubility (TCPP: 1600; TCEP: $7000 \mathrm{mg} / \mathrm{L}$ ) in water and the widely applications (Table S2) in Beijing. This result was consistent with the investigation by Shi (Shi et al., 2016) in which TCPP and TCEP were the most abundant compounds in Beijing surface water in 2013-2014, with average concentration of $291 \mathrm{ng} / \mathrm{L}$ and $219 \mathrm{ng} / \mathrm{L}$, respectively.

The concentration of all chlorinated OPFRs (i.e. TCPP, TCEP and TDCPP) were significantly higher than aryl-OPFRs (i.e. TPP and TCP) $(P<0.05)$, mostly because that the chlorinated OPFRs are considered as very persistent and were not degraded during wastewater treatment (Marklund et al., 2005). There shows different characteristics of the fate of aryl and chlorinated OPFRs in surface water and underground water (Fig. 2). For the former, the concentration was equal or a little higher in the underground water. However, the concentration of chlorinated OPFRs was much higher in surface water than those in underground water. That may because the aryl-OPFRs have a higher logk $\mathrm{ow}_{\mathrm{w}}$ (Table S2) thus was trapped in the soil. In addition, the OPFRs concentration at different sampling points, especially TCPP, has 
obvious spatial difference, but has no obvious regularity along the water flow direction (Fig. 2). What we would like to emphasize is that the trace amounts of OPFRs in groundwater also had a potential threat to aquatic life and human health, which should be further addressed. Notably, the sampling time of this study was in winter, and the average temperature is usually $20 \sim 25^{\circ} \mathrm{C}$ lower than summer, Regnery and Püttmann (2009) found that the proportions of OPFRs in condensate and internal vehicle air reveal an increase as the temperature goes up. Therefore, it is foreseeable that the emissions of ORFPs, especially the more volatile ORFPs (TCPP and TCEP etc.), from vehicles and buildings will be higher in summer than in winter, which means that there is still a more serious risk of OPFRs exposure in Beijing's surface water and groundwater.

\subsection{Occurrence and removal efficiency of OPFRs in STPs 3.2.1 Occurrence OPFRs in STPs}

We detected the distribution of OPFRs in the influent and effluent water in STPs (Fig. 3a). The total concentration of OPFRs in STPs ranges from $57.09 \sim 535.09$ (mean: 296.91) ng/L, which are lower than that in surface water and higher than that in groundwater. Undoubtedly, in densely populated cities, domestic sewage is the main source of OPFRs, which is directly related to human health (Kim et al., 2017), and the concentration of OPFRS in the downstream of STPs has increased significantly (Andresen et al., 2004).

In our study, the content of STPs influent may reflect the relative degree of the application of different OPFRs. For the influent of the STP in Miyun District, the concentration of TCPP was highest with a concentration between $40.94 \sim 216.01 \mathrm{ng} / \mathrm{L}$, which was persistence with the concentration in surface water. TCPP was the most abundant OPFRs in research of Martínez-Carballo et al. (Martínez-Carballo et al., 2007). The secondary predominant compound was TCEP (15.50 $39.10 \mathrm{ng} / \mathrm{L})$, followed by TDCPP (ND $24.80 \mathrm{ng} / \mathrm{L}$ ). The distribution of OPFRs in the distribution was persistence with the surface water. In the research of Kim et al. (2017), TBOEP was the predominant compound in the influent of a STP in Albany area of New York State followed by TCPP with a concentration of $5120 \mathrm{ng} / \mathrm{L}$, much higher than this study as well as TDCPP $(1720 \mathrm{ng} / \mathrm{L})$ and TCEP $(1430 \mathrm{ng} / \mathrm{L})$. Interestingly, there shows a higher content of TCPP in Miyun STP which may be related with the contribution of industry. According to the "13th Five-Year Plan" (2015 2020), general manufacturing should be evacuated from the six core districts including Chaoyang and Haidian. Besides, the leaching from the plastic films used for agriculture (Cho et al., 1996) may be one of the reasons causing the increase of TCP in Miyun.

\subsubsection{Removal efficiency of OPFRs in STPs}

Generally speaking, the concentration of most pollutants in the influent of STPs can be reduced, but not all pollutants were always satisfactorily removed (Liang et al., 2016; Pang et al., 2016b). There showed different treatment rate in STPs as sees in Fig. 3b. As the concentration of some OPFRs in the influents were none detected, the removal rate was not reflected in the figure. What shocked us was that the removal efficiency of OPFRs in STPs was even more unsatisfactory, or even negative, with a total removal 
rate of $-856.67 \% \sim 55.15 \%$ (Table S3). For TCPP, the major pollution factors in STPs, its total removal efficiency was from $-398.23 \%$ to $-35.83 \%$ in municipal STPs. The treatment rate of STPs for OPFRs may related with the physical chemistry properties and influent concentration of different OPFRs, or technique of STPs, such as retention times. It showed that linear alkyl OPFRs are easier to be degraded than branched compounds, and chlorinated OPFRs are more persistent than non-chlorinated ones (Liang and Liu, 2016; Reemtsma, et al., 2008). The removal rate of TBEP was reported to be $85.10 \%$ 88.40\% (Pang et al., 2016). In this study, the treatment rates of all the chlorinated OPFRs were negative, showing strong resistance to biotransformation. There was a remarkable growth in effluent for TCPP, TCEP and TDCPP, which was similar with the STPs studied by other scientists (Marklund et al., 2005; Meyer and Bester, 2004; Shi et al., 2016). Merely $0.30 \%$ of TCEP and $4.00 \%$ of TCPP was removed in Pang's studies (Pang et al., 2016), however, TPP could be removed with a rate of about $80 \%$ in the same STP.

The worst removal capabilities were found at the STP in Chaoyang District, which applied the cyclic activated sludge technology (CAST) (STP in Chaoyang District). The reason may be that the large quantity recycling of activated sludge with high mass flow of OPFRs from the return sludge and internal recirculation sludge, the chlorinated OPFRs are easily absorbed by the biological particles and the coarse particles (Liang and Liu, 2016), and the sludge is refluxed in the primary sedimentation tank or the secondary sedimentation tank, thereby causing an analytical effect to increase the concentration of OPFRs in the effluent. Therefore, the STPs are unsuitable to handle the chlorinated OPFRs. However, compared with CAST and $\mathrm{A}^{2} / \mathrm{O}$ (STP in Miyun District), A/O MBR technology may be more effective for the removal of OPFRs, which showed the high removal efficiencies for TCP.

However, researches showed that the sorption of OPRFs to sludge happened to some extends. In Bester's (Bester, 2005) study, the average concentration of TCPP in sludge from 20 German STPs was $5000 \mathrm{ng} / \mathrm{g}$. In one wastewater treatment plant sludges from the Pearl River Delta, the concentration of OPRFs in sewage sludge was $96.70 \sim 1312.90 \mathrm{ng} / \mathrm{g}$ (Zeng et al., 2014). TCEP had a removal rate of about $20 \%$ in Reemtsma's (Reemtsma et al., 2006) STPs. Unlike Meyer and Bester's survey (Meyer and Bester, 2004), the treatment rate was rather lower in this paper, which may because the process of STPs have little effect for low concentration of TPP. In general, the anaerobic-anoxic-oxic process exhibited higher removal rate than the anoxic-oxic process for TCEP and TCPP. Pang's (Pang et al., 2016) research further showed activated sludge adsorption was the major process for TCPP removed in the anoxic-oxic press.

The STPs had a certain treatment effect on the alkyl OPFRs, and the effluent concentration of TPP was lower than the influent (Table S3). Some articles had showed that the occurrence and distribution were persistence with the density of population (Shi et al., 2016), and higher concentrations of OPFRs were often found in metropolitan areas (Kim and Kannan, 2018).

\subsection{Ecological risk assessment}

The continuous inputs and potential toxicity of OPFRs have drawn an increasing concern on their effects towards the ecosystem. In this study, the risk assessment to aquatic organisms was estimated for the most frequently detected OPFRs, including TPP, TCP, TCPP, TCEP and TDCPP in the multiple urban water 
bodies of Beijing. Acute median effective concentrations $\left(\mathrm{LC}_{50}\right.$ or $\left.\mathrm{EC}_{50}\right)$ of 5 OPFRs for different aquatic organisms (algae, fish and crustacean) were obtained according to the Environmental Risk Limits report for organophosphorus flame retardants (Verbruggen et al., 2006). As shown in Table 1, low $(R Q<0.1)$ risk of 5 OPFRs was observed for three organisms in urban water from Beijing. In addition, the risks of the five OPFRs in multiple urban water bodies were different. The RQ values of TCPP and TDCPP in Wenyu River and the three STPs are relatively higher than in groundwater (Table S1), indicating that the TCPP and TDCPP in surface water and domestic wastewater in Beijing may be the main contributors to potential aquatic ecological risks.

Previous reports had confirmed that OPFRs (such as TPP, TCP, TCEP, etc.) can exist and accumulate in organisms (Guo et al., 2017; Kim et al., 2011; Van et al., 2012), even TCPP ( LogK $_{\text {ow }}=2.59$; Table S2) with a low octanol-water partition coefficient (Reemtsma et al., 2008). TPP has less impact on human health but is more toxic to aquatic ecosystems (McPherson et al., 2004). For the chronic toxicity an estimated NOEC of TPP for daphnia and fish were $0.1 \mathrm{mg} / \mathrm{L}$ and $0.0014 \mathrm{mg} / \mathrm{L}$, respectively, which levels were highly regarded by the US-EPA (2007). Since the highest concentration detected for TPP in multiple urban water was $2.42 \mathrm{ng} / \mathrm{L}$,and its MEC/PNEC ratio were $2.40 \cdot 10^{-5}$ (daphnia) and $0.60 \cdot 10^{-2}$ (fish), which means no chronic adverse effects are expected. However, it cannot be ignored that the degradation efficiency of these OPFRs in organisms is generally low, chronic toxicity will still occur under long-term accumulation, which ultimately endanger ecological health (Wei et al., 2015; Van et al., 2016). Therefore, it is necessary to further investigate the occurrence characteristics of OPFRs in aquatic environment and its bioaccumulation and bio-amplification in biota for a more comprehensive risk assessment. 
Table 1

$\mathrm{RQs}$ for the aquatic organisms as calculated from MECs and PNECs

\begin{tabular}{|c|c|c|c|c|c|c|c|c|}
\hline \multirow[t]{2}{*}{ Analytes } & \multirow[t]{2}{*}{ Organisms } & \multirow{2}{*}{$\begin{array}{l}\mathrm{L}(\mathrm{E}) \mathrm{C}_{50}{ }^{\mathrm{a}} \\
(\mathrm{mg} / \mathrm{L})\end{array}$} & \multirow[t]{2}{*}{$\mathrm{AF}$} & \multirow{2}{*}{$\begin{array}{l}\text { PNEC } \\
(\mathrm{ng} / \mathrm{L})\end{array}$} & \multicolumn{2}{|c|}{ MEC (ng/L) } & \multicolumn{2}{|l|}{ RQs } \\
\hline & & & & & Min & Max & Min & Max \\
\hline \multirow[t]{3}{*}{ TCEP } & $\begin{array}{l}\text { Algae } \\
\text { (Scenedesmus } \\
\text { subspicatus) }\end{array}$ & 51.0 & 1000 & 51000 & 3.30 & 169.37 & $\begin{array}{l}6.46 \mathrm{E}- \\
05\end{array}$ & $\begin{array}{l}3.32 \mathrm{E}- \\
03\end{array}$ \\
\hline & $\begin{array}{l}\text { Crustacean } \\
\text { (Daphnia magna) }\end{array}$ & 330.0 & 1000 & 330000 & & & $\begin{array}{l}9.98 \mathrm{E}- \\
06\end{array}$ & $\begin{array}{l}5.13 \mathrm{E}- \\
04\end{array}$ \\
\hline & $\begin{array}{l}\text { Fish (Carassius } \\
\text { auratus) }\end{array}$ & 90.0 & 1000 & 90000 & & & $\begin{array}{l}3.66 \mathrm{E}- \\
05\end{array}$ & $\begin{array}{l}1.88 \mathrm{E}- \\
03\end{array}$ \\
\hline \multirow[t]{3}{*}{ TCPP } & $\begin{array}{l}\text { Algae } \\
\text { (Scenedesmus } \\
\text { subspicatus) }\end{array}$ & 45.0 & 1000 & 45000 & 12.02 & 394.77 & $\begin{array}{l}2.67 \mathrm{E}- \\
04\end{array}$ & $\begin{array}{l}8.77 \mathrm{E}- \\
03\end{array}$ \\
\hline & $\begin{array}{l}\text { Crustacean } \\
\text { (Daphnia magna) }\end{array}$ & 91.0 & 1000 & 91000 & & & $\begin{array}{l}1.32 \mathrm{E}- \\
04\end{array}$ & $\begin{array}{l}4.34 \mathrm{E}- \\
03\end{array}$ \\
\hline & $\begin{array}{l}\text { Fish (Carassius } \\
\text { auratus) }\end{array}$ & 30.0 & 1000 & 30000 & & & $\begin{array}{l}4.01 \mathrm{E}- \\
04\end{array}$ & $\begin{array}{l}1.32 \mathrm{E}- \\
02\end{array}$ \\
\hline \multirow[t]{3}{*}{ TDCPP } & $\begin{array}{l}\text { Algae } \\
\text { (Scenedesmus } \\
\text { subspicatus) }\end{array}$ & 39.0 & 1000 & 39000 & ND & 76.85 & / & $\begin{array}{l}1.97 \mathrm{E}- \\
03\end{array}$ \\
\hline & $\begin{array}{l}\text { Crustacean } \\
\text { (Daphnia magna) }\end{array}$ & 4.20 & 1000 & 4200 & & & / & $\begin{array}{l}1.83 \mathrm{E}- \\
02\end{array}$ \\
\hline & $\begin{array}{l}\text { Fish (Carassius } \\
\text { auratus) }\end{array}$ & 5.10 & 1000 & 5100 & & & / & $\begin{array}{l}1.51 \mathrm{E}- \\
02\end{array}$ \\
\hline \multirow[t]{3}{*}{ TCP } & $\begin{array}{l}\text { Algae } \\
\text { (Scenedesmus } \\
\text { subspicatus) }\end{array}$ & 0.29 & 1000 & 290 & ND & 0.46 & / & $\begin{array}{l}1.57 \mathrm{E}- \\
03\end{array}$ \\
\hline & $\begin{array}{l}\text { Crustacean } \\
\text { (Daphnia magna) }\end{array}$ & 0.27 & 1000 & 270 & & & / & $\begin{array}{l}1.69 \mathrm{E}- \\
03\end{array}$ \\
\hline & $\begin{array}{l}\text { Fish (Carassius } \\
\text { auratus) }\end{array}$ & 0.11 & 1000 & 110 & & & I & $\begin{array}{l}4.15 \mathrm{E}- \\
03\end{array}$ \\
\hline \multirow[t]{3}{*}{ TPP } & $\begin{array}{l}\text { Algae } \\
\text { (Scenedesmus } \\
\text { subspicatus) }\end{array}$ & 0.50 & 1000 & 500 & 0.52 & 2.42 & $\begin{array}{l}1.03 \mathrm{E}- \\
03\end{array}$ & $\begin{array}{l}4.83 \mathrm{E}- \\
03\end{array}$ \\
\hline & $\begin{array}{l}\text { Crustacean } \\
\text { (Daphnia magna) }\end{array}$ & 1.00 & 1000 & 1000 & & & $\begin{array}{l}5.17 \mathrm{E}- \\
04\end{array}$ & $\begin{array}{l}2.42 \mathrm{E}- \\
03\end{array}$ \\
\hline & $\begin{array}{l}\text { Fish (Carassius } \\
\text { auratus) }\end{array}$ & 0.70 & 1000 & 700 & & & $\begin{array}{l}7.39 \mathrm{E}- \\
04\end{array}$ & $\begin{array}{l}3.45 \mathrm{E}- \\
03\end{array}$ \\
\hline
\end{tabular}


L(E)C50: lowest median effective concentration value obtained from existing studies.

AF: the evaluation factor.

PNEC: the predicted no-effect concentration of organophosphate flame retardants (OPFRs).

MEC: the measured environmental concentration of OPFRs.

$R Q$ : the environmental risk quotient of OPFRs.

\section{Conclusion}

In the present study, the occurrence and distribution of 6 OPFRs in urban multiple water of Beijing, China were explored. Five OPFRs were detected in the urban water samples, and TCPP were the most abundant compounds followed by TCEP and TDCPP. The order of concentration of OPFRs from high to low is:

surface water, the effluent and influent of STP and underground water. The levels of chlorinated OPFRs in urban surface water in Beijing were higher than or similar to those detected in most of other sites in literature. Risk assessment based on acute toxicity data suggested the low risk of OPFRs to three aquatic organisms (algae, crustacean and fish). However, taking into account the high levels of OPFRs in surface water and STPs in Beijing, long-term exposure of the human body and bioaccumulation of these contaminants in aquatic environment should be further explored.

\section{Declarations}

\section{Acknowledgements}

This work was financially supported by the National Natural Science Foundation of China (41877409) and Ministry of Science and Technology of China (Grant No. 2015FY110900).

\section{References}

1. Andresen, J., Grundmann, A., Bester, K. (2004). Organophosphorus flame retardants and plasticisers in surface waters. Science of the total environment, 332(1-3), 155-166.

2. Bester, K. (2005). Comparison of TCPP concentrations in sludge and wastewater in a typical German sewage treatment plant-comparison of sewage sludge from 20 plants. Journal of Environmental Monitoring, 7(5), 509-513.

3. Cho, K. J., Hirakawa, T., Mukai, T., Takimoto, K., Okada, M. (1996). Origin and stormwater runoff of TCP (tricresyl phosphate) isomers. Water research, 30(6), 1431-1438.

4. Ding, J., Shen, X., Liu, W., Covaci, A., \& Yang, F. (2015). Occurrence and risk assessment of organophosphate esters in drinking water from Eastern China. Science of the Total Environment, 538, 959-965. 
5. Kemmlein, S., Hahn, O., \& Jann, O. (2003). Emissions of organophosphate and brominated flame retardants from selected consumer products and building materials. Atmospheric environment, 37(39-40), 5485-5493.

6. Kim, U.-J., Kannan, K. (2018). Occurrence and distribution of organophosphate flame retardants/plasticizers in surface waters, tap water, and rainwater: implications for human exposure. Environmental science \& technology, 52(10), 5625-5633.

7. Kim, U.-J., Oh, J. K., Kannan, K. (2017). Occurrence, removal, and environmental emission of organophosphate flame retardants/plasticizers in a wastewater treatment plant in New York State. Environmental science \& technology, 51(14), 7872-7880.

8. Lee, S., Jeong, W., Kannan, K., Moon, H.-B. (2016). Occurrence and exposure assessment of organophosphate flame retardants (OPFRs) through the consumption of drinking water in Korea. Water research, 103, 182-188.

9. Liang, K., Liu, J. (2016). Understanding the distribution, degradation and fate of organophosphate esters in an advanced municipal sewage treatment plant based on mass flow and mass balance analysis. Science of the Total Environment, 544, 262-270.

10. Loos, R., Carvalho, R., António, D. C., Comero, S., Locoro, G., Tavazzi, S., et al. (2013). EU-wide monitoring survey on emerging polar organic contaminants in wastewater treatment plant effluents. Water research, 47(17), 6475-6487.

11. Marklund, A., Andersson, B., Haglund, P. (2003). Screening of organophosphorus compounds and their distribution in various indoor environments. Chemosphere, 53(9), 1137-1146.

12. Marklund, A., Andersson, B., Haglund, P. (2005). Organophosphorus flame retardants and plasticizers in Swedish sewage treatment plants. Environmental science \& technology, 39(19), 7423-7429.

13. Martínez-Carballo, E., González-Barreiro, C., Sitka, A., Scharf, S., Gans, O. (2007). Determination of selected organophosphate esters in the aquatic environment of Austria. Science of the total environment, 388(1-3), 290-299.

14. Meyer, J., Bester, K. (2004). Organophosphate flame retardants and plasticisers in wastewater treatment plants. Journal of Environmental Monitoring, 6(7), 599-605.

15. Möller, A., Sturm, R., Xie, Z., Cai, M., He, J., Ebinghaus, R. (2012). Organophosphorus flame retardants and plasticizers in airborne particles over the Northern Pacific and Indian Ocean toward the polar regions: Evidence for global occurrence. Environmental science \& technology, 46(6), 3127-3134.

16. Pang, L., Yang, P., Zhao, J., Zhang, H. (2016). Comparison of wastewater treatment processes on the removal efficiency of organophosphate esters. Water Science and Technology, 74(7), 1602-1609.

17. Reemtsma, T., Quintana, J. B., Rodil, R., Garcı, M., Rodrı, I. (2008). Organophosphorus flame retardants and plasticizers in water and air I. Occurrence and fate. TrAC Trends in Analytical Chemistry, 27(9), 727-737.

18. Reemtsma, T., Weiss, S., Mueller, J., Petrovic, M., González, S., Barcelo, D., et al. (2006). Polar pollutants entry into the water cycle by municipal wastewater: a European perspective.

Environmental Science \& Technology, 40(17), 5451-5458. 
19. Schreder, E. D., La Guardia, M. J. (2014). Flame retardant transfers from US households (dust and laundry wastewater) to the aquatic environment. Environmental science \& technology, 48(19), 1157511583.

20. Shi, Y., Gao, L., Li, W., Wang, Y., Liu, J., Cai, Y. (2016). Occurrence, distribution and seasonal variation of organophosphate flame retardants and plasticizers in urban surface water in Beijing, China. Environmental pollution, 209, 1-10.

21. Stevens, R., Van Es, D. S., Bezemer, R., Kranenbarg, A. (2006). The structure-activity relationship of fire retardant phosphorus compounds in wood. Polymer Degradation and Stability, 91(4), 832-841.

22. Takigami, H., Suzuki, G., Hirai, Y., Ishikawa, Y., Sunami, M., \& Sakai, S.-i. (2009). Flame retardants in indoor dust and air of a hotel in Japan. Environment international, 35(4), 688-693.

23. Van der Veen, I., de Boer, J. (2012). Phosphorus flame retardants: properties, production, environmental occurrence, toxicity and analysis. Chemosphere, 88(10), 1119-1153.

24. Verbruggen, E., Rila, J., Traas, T., Posthuma-Doodeman, C., Posthumus, R. (2006). Environmental Risk Limits for several phosphate esters, with possible application as flame retardant. RIVM rapport 601501024.

25. Wei, G.-L., Li, D.-Q., Zhuo, M.-N., Liao, Y.-S., Xie, Z.-Y., Guo, T.-L., et al. (2015). Organophosphorus flame retardants and plasticizers: sources, occurrence, toxicity and human exposure. Environmental Pollution, 196, 29-46.

26. Yadav, I. C., Devi, N. L., Li, J., Zhang, G., Covaci, A. (2018). Concentration and spatial distribution of organophosphate esters in the soil-sediment profile of Kathmandu Valley, Nepal: implication for risk assessment. Science of The Total Environment, 613, 502-512.

27. Zeng, X., He, L., Cao, S., Ma, S., Yu, Z., Gui, H., et al. (2014). Occurrence and distribution of organophosphate flame retardants/plasticizers in wastewater treatment plant sludges from the Pearl River Delta, China. Environmental toxicology and chemistry, 33(8), 1720-1725.

28. Zhong, M., Tang, J., Mi, L., Li, F., Wang, R., Huang, G., et al. (2017). Occurrence and spatial distribution of organophosphorus flame retardants and plasticizers in the Bohai and Yellow Seas, China. Marine pollution bulletin, 121(1-2), 331-338.

\section{Figures}




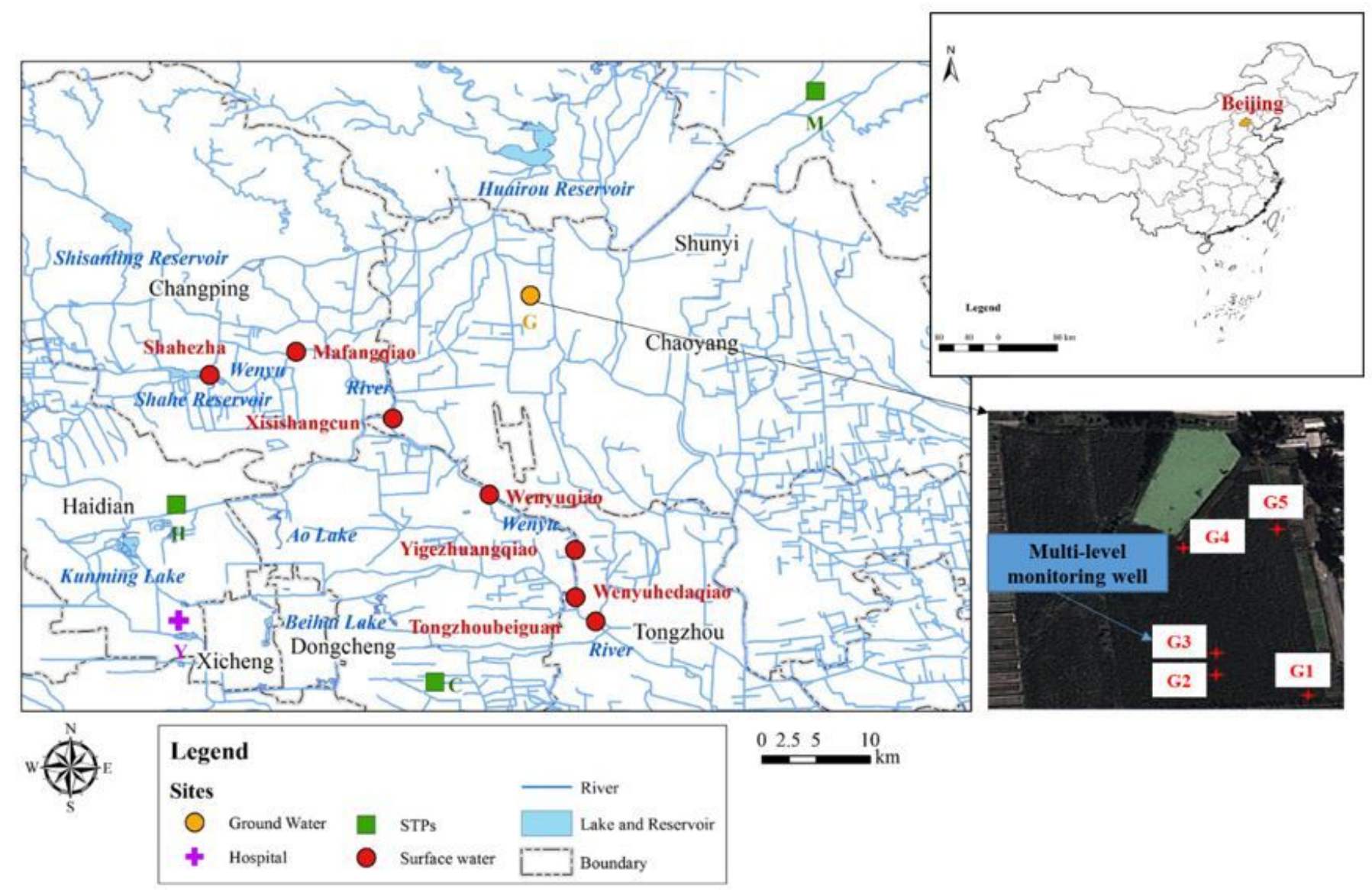

Figure 1

Sampling locations of surface water, groundwater and sewage treatment plants (STPs) samples in urban Beijing, China. Note: The designations employed and the presentation of the material on this map do not imply the expression of any opinion whatsoever on the part of Research Square concerning the legal status of any country, territory, city or area or of its authorities, or concerning the delimitation of its frontiers or boundaries. This map has been provided by the authors. 


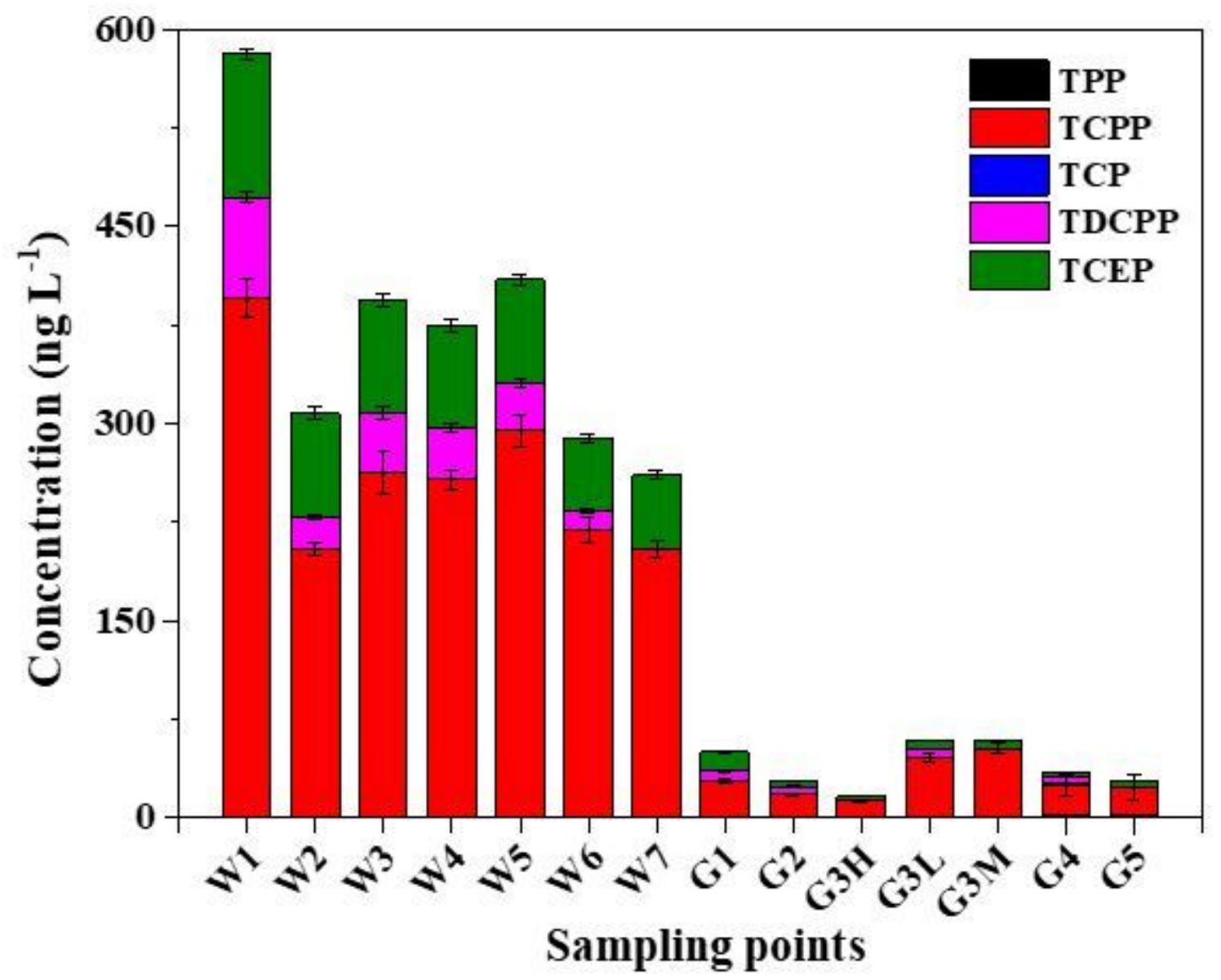

Figure 2

Concentration of OPFRs in surface water and groundwater.

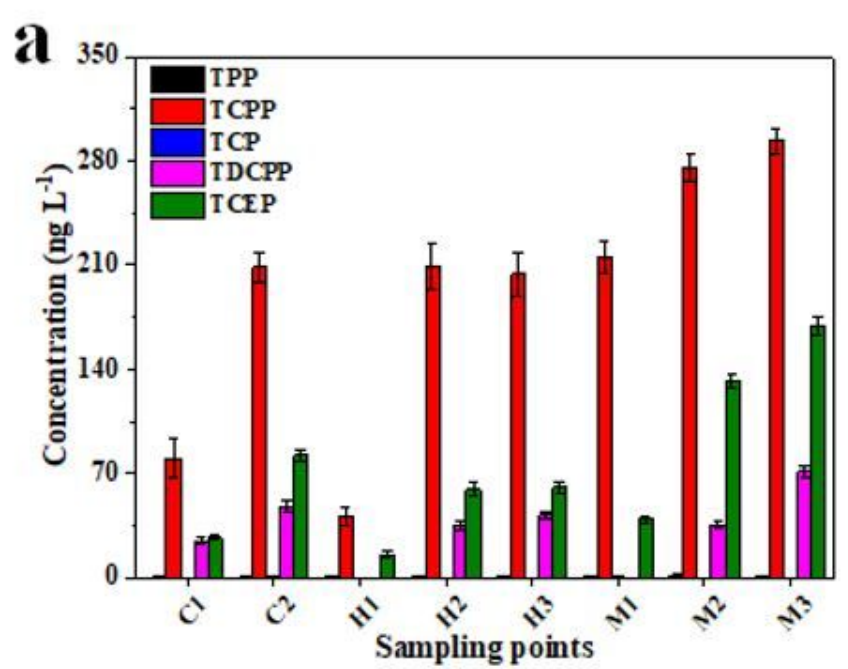

b

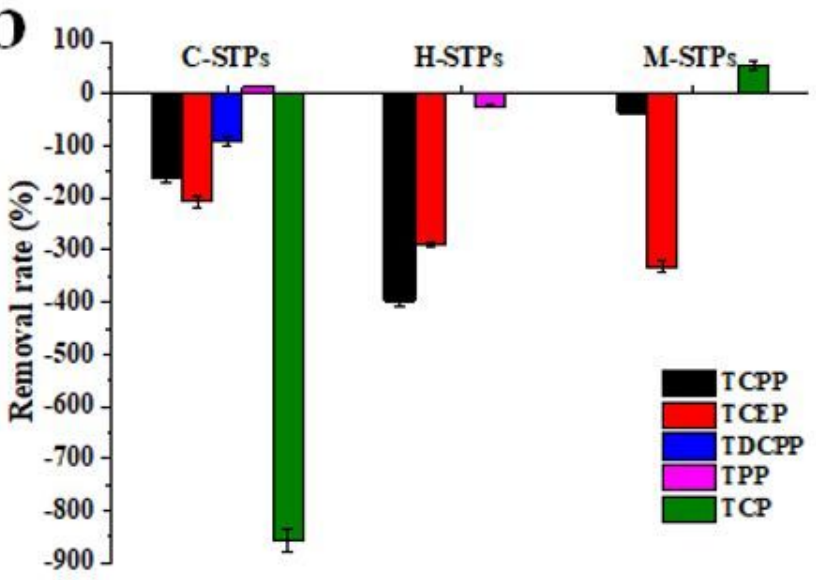


Figure 3

(a) Concentration of OPFRs in three STPs. (b) Removal rate of OPFRs in three STPs.

\section{Supplementary Files}

This is a list of supplementary files associated with this preprint. Click to download.

- Supplementallnformation.docx 